\title{
EFEKTIFITAS MENYIKAT GIGI MENGGUNAKAN SIWAK DALAM MENURUNKAN INDEKS PLAK PADA SISWA MTs SWASTA ALWASLIYAH DESA LAMA KECAMATAN PANCUR BATU DELI SERDANG TAHUN 2014
}

\author{
Adriana Hamsar, Cut Aja Nuraskin, Manta Rosma \\ Jurusan Keperawatan Gigi Poltekkes Kemenkes Medan
}

\begin{abstract}
Abstrak
Siwak berbentuk batang yang diambil dari akar dan ranting tanaman arak (salvadora persica) yang berdiameter mulai dari $0,1 \mathrm{~cm}$ sampai $5 \mathrm{~cm}$. Pohon arak adalah pohon yang kecil seperti belukar dengan batang yang bercabang-cabang, berdiameter lebih dari 1 kaki, jika kulitnya dikelupas berwarna agak keputihan dan memilki jutaan serat, yang berguna membersihkan gigi. Jenis penelitian adalah eksperimen semu (quasi eksperiment) dengan rancangan pre-test dan post-test only group design. Penelitian ini dilakukan pada Siswa/i MTs Al-Wasliyah Pancur Batu Deli Serdang dengan jumlah populasi 214 orang dengan pengambilan sampel dilakukan secara acak yaitu berjumlah 40 orang. Hasil yang didapat dalam penelitian ini menunjukkan bahwa menyikat gigi dengan siwak lebih efektif dalam menurunkan Indeks plak dibandingkan dengan sikat gigi biasa. Hal ini dapat dilihat dari perbedaan penurunan plak indeks, penggunaan siwak penurunannya sebesar 1.39. sedangkan sikat gigi penurunan plak indeksnya sebesar 1.31. Kesimpulan dari penelitian ini yaitu ada perbedaan menyikat gigi dengan siwak dan sikat gigi terhadap penurunan indeks plak. Menyikat gigi dengan siwak lebih efektif dari pada sikat gigi. Hal ini menunjukkan bahan tradisional dapat digunakan untuk membersihkan gigi dan mulut.
\end{abstract}

Kata kunci : Siwak, sikat gigi, Indeks Plak

\section{PENDAHULUAN}

Dalam UU Kesehatan No. 23 Tahun 1992 Pasal 10 dinyatakan bahwa: "Untuk mewujudkan derajat kesehatan yang optimal bagi masyarakat, diselenggarakan upaya kesehatan dengan pendekatan pemeliharaan, peningkatan pencegahan, pengobatan dan pemulihan yang dilaksanakan secara terpadu dan berkesinambungan".

Masa anak sekolah merupakan masa untuk meletakkan landasan yang kokoh bagi terwujudnya manusia yang berkualitas dan kesehatan merupakan faktor penting yang menentukan kualitas sumber daya manusia. Dalam rangka meningkatkan kualitas kesehatan siswa di sekolah, kesehatan gigi dan mulut merupakan suatu bagian dari kesehatan umum yang mempunyai peran penting dalam fungsi pengunyahan dan kecantikan.

Siwak atau Miswak merupakan bagian dari batang akar atau ranting tumbuhan salvadora persica yang kebanyakan tumbuh di daerah Timur Tengah Asia dan Afrika. Siwak berbentuk batang yang diambil dari akar dan ranting tanaman arak (salvadora persica) yang berdiameter mulai dari $0,1 \mathrm{~cm}$ sampai $5 \mathrm{~cm}$. Pohon arak adalah pohon yang kecil seperti belukar dengan batang yang bercabang-cabang, berdiameter lebih dari 1 kaki, jika kulitnya dikelupas berwana agak keputihan dan memilki banyak jutaan serat. Akarnya berwarna cokelat dan bagian dalamnya berwarna putih.
Aromanya seperti seledri dan rasanya agak pedas. (Bastomi Ali. 2011).

Sikat gigi adalah alat untuk membersihkan gigi yang berbentuk sikat kecil dengan pegangan. Pasta gigi biasanya ditambah kesikat gigi sebelum menggosok gigi. Sikat gigi banyak jenisnya, dari yang bulunya halus sampai kasar, bentuknya kecil sampai besar dan berbagai desain pegangan. Kebanyakan dokter gigi menganjurkan penggunaan sikat gigi yang lembut meskipun sikat gigi berbulu lembut kurang efektif membersihkan sela-sela gigi.Sikat gigi berbulu keras dapat merusak lapisan enamel dan melukai gusi. (Wikipedia.2007).

Menurut para dokter gigi menyikat gigi dilakukan minimal dua kali sehari yaitu pagi sesudah makan malam sebelum tidur. Menyikat gigi juga dianjurkan menggunakan pasta gigi yang membantu membersihkan gigi lebih bersih dan wangi. Akibat dari jarangnya menyikat gigi adalah timbulnya plak gigi yang diakibatkan dari penumpukan kotoran di gigi. Plak gigi juga dapat menyebabkan gigi berlubang yang jika dibiarkan bisa membuat gigi ngilu dan bau napas yang tidak sedap.

Survei awal telah dilakukan pemeriksaan terhadap indeks plak di MTs Al-Wasliyah pada siswa/i kelas II menunjukkan bahwa kriteria plak siswa/i tersebut rata-rata dikategorikan buruk. Faktor yang mempengaruhi hal tersebut rata-rata adalah kurangnya pengetahuan 
siswa/i MTs Al-Wasliyah Pancur Batu tentang kebersihan gigi dan mulut.

\section{Tujuan Penelitian \\ Tujuan Umum}

Penelitian ini bertujuan untuk mengetahui efektifitas penggunaan siwak dan sikat gigi dalam menurunkan indeks plak pada siswa MTs Alwasliyah Pancur Batu Medan Tahun 2014.

\section{Tujuan Khusus}

1. Untuk mengetahui Indeks Plak rata-rata sebelum dan sesudah menyikat gigi dengan siwak pada MTs Alwasliyah Pancur Batu Medan Tahun 2014.

2. Untuk mengetahui Indeks Plak rata-rata sebelum dan sesudah menyikat gigi dengan sikat gigi pada MTs Alwasliyah Pancur Batu Medan Tahun 2014.

3. Untuk mengetahui persentase kriteria indeks plak pada MTs Alwasliyah .

\section{Manfaat Penelitian}

1. Hasil Penelitian diharapkan dapat menambah wawasan dan ilmu pengetahuan bagi MTs Alwasliyah Pancur Batu Medan Tahun 2014 tentang Siwak dan sikat gigi

2. Hasil penelitian ini diharapkan dapat menjadi bahan masukan bagi penelitian lain.

\section{Hipotesis}

1. Hipotessi $\mathrm{Nol}$ (Ho)

Tidak ada perbedaan menyikat gigi dengan sikat gigi dan siwak terhadap penurunan indeks plak.

2. Hipotesis Alternatif (Ha)

Ada perbedaan menyikat gigi dengan sikat gigi dan siwak terhadap penurunan indeks plak

\section{METODE PENELITIAN}

\section{Jenis Penelitian}

Jenis penelitian yang dilakukan adalah penelitian eksperimen semu (quasi eksperiment) dengan rancangan pre-test dan post-test only group design untuk melihat keefektifan menyikat gigi dengan sikat gigi dan siwak pada Siswa/i MTs Al- Wasliyaah Pancur Batu Medan, sehingga dapat ditulis dengan rumus:

$$
\mathrm{R}=\frac{01(\mathrm{X} 1) 02}{03(\mathrm{X} 2) 04}
$$

Keterangan :

$$
\begin{aligned}
& \mathrm{R}=\text { Randomization } \\
& \text { O1 = Observasi } 1 \text { perlakuan mengukur indeks } \\
& \text { plak sebelum menggunakan siwak } \\
& \mathrm{O} 2=\text { Observasi } 1 \text { perlakuan mengukur indeks } \\
& \text { plak sesudah menggunakan siwak } \\
& \text { O3 = Observasi } 1 \text { perlakuan mengukur indeks } \\
& \text { plak sebelum menggunakan sikat gigi }
\end{aligned}
$$

$$
\begin{aligned}
& \mathrm{O} 4=\begin{array}{c}
\text { Observasi } 1 \text { perlakuan mengukur indeks } \\
\text { plak sesudah menggunakan sikat gigi }
\end{array} \\
& \mathrm{X} 1=\text { perlakuan menggunakan siwak } \\
& \mathrm{X} 2=\text { perlakuan menggunakan sikat gigi }
\end{aligned}
$$

\section{Populasi dan sampel \\ Populasi}

Populasi adalah keseluruhan Siswa/i Kelas II MTs Al-Wasliyah Pancur batu Desa Lama Kecamatan Pancur batu Medan 214

\section{Sampel}

Sampel dalam penelitian ini adalah yang berjumlah 40 orang, dibagi menjadi 2 kelompok, masingmasing kelompok terdiri dari 20 orang. Kelompok pertama menggunakan siwak, dan kelompok kedua menggunakan sikat gigi biasa.

\section{Jenis dan cara Pengumpulan Data}

Data yang diambil dalam penelitian ini adalah data primer dan data sekunder dengan melakukan pemeriksaan langsung pada Siswa/i Kelas II MTs. AlWasliyah Pancur batu Desa Lama Kecamatan

Pancur batu. Data primer adalah data yang diambil langsung peneliti dari pemeriksaan langsung ke mulut siswa/i yang menjadi sampel dengan mencatat hasil pemeriksaan plak siswa/i. Sedangkan data skunder adalah data yang diperoleh dari pihak sekolah tentang data jumlah siswa/i Kelas II MTs. Al-Wasliyah Pancur Batu Desa Lama Kecamatan Pancur batu.

\section{Analisa Data}

Analisa data yang digunakan dalam penelitian ini adalah teknik kuantitatif data yang telah dikumpulkan dan dianalisis secara analitik kemudian disajikan dalam bentuk tabel distribusi frekuensi dengan tabel silang $2 \times 3$. Analisa data menggunakan Uji Mann-whitney untuk dapat menyimpulkan adanya hubungan 3 (tiga) variabel (independent, dependent dan confounding) bermakna atau tidak untuk mengetahui pengaruh menyikat gigi dengan siwak dan sikat gigi terhadap indeks plak.

\section{Hasil Penelitian}

Data yang dikumpulkan adalah hasil penelitian yang dilakukan terhadap siswa/i kelas II MTs Alwasliayah Pancur Batu Medan. Pengumpulan data dilakukan dengan pemeriksaan langsung kemulut siswa/i yang menjadi sampel. Setelah seluruh data terkumpul, membuat analisa data dengan membuat tabel distribusi frekuensi untuk masing-masing. Kemudian dilakukan pengolahan data secara statistik yaitu menggunakan uji Man-Whitney.

Tabel 1. Distribusi Frekuensi Berdasarkan Jenis Kelamin Pada Siswa-Siswi Kelas II MTs Al-Wasliyah Pancur Batu Medan

\begin{tabular}{ccc}
\hline Jenis Kelamin & Jumlah & Persentase \\
\hline Laki-laki & 17 & 42.5 \\
Perempuan & 23 & 57.5 \\
\hline Total & 40 & 100 \\
\hline
\end{tabular}


Tabel 2. Distribusi Frekuensi Rata-Rata Plak Indeks Pada Siswa-Siswi Kelas II MTs Al-Wasliyah Pancur Batu Medan

\begin{tabular}{|c|c|c|}
\hline Jenis & \multicolumn{2}{|c|}{ Rata-rata Plak Indakes } \\
\hline Penggunaan & Sebelum & Sesudah \\
\hline Siwak & 1.90 & 0.51 \\
\hline Sikat Gigi & 1.95 & 0.64 \\
\hline
\end{tabular}

Tabel 3. Distribusi Frekuensi Persentase Kriteria Plak Indeks Sebelum dan Sesudah Menggunakan Siwak Pada Siswa-Siswi MTs Al Wasliyah Pancur Batu Medan

\begin{tabular}{ccccc}
\hline $\begin{array}{c}\text { Kriteria } \\
\text { Plak }\end{array}$ & \multicolumn{2}{c}{$\begin{array}{c}\text { Sebelum Menyikat } \\
\text { Gigi Dengan Siwak }\end{array}$} & \multicolumn{2}{c}{$\begin{array}{c}\text { Sesudah Menyikat } \\
\text { Gigi Dengan } \\
\text { Siwak }\end{array}$} \\
Indeks & $\mathrm{N}$ & $\%$ & $\mathrm{~N}$ & $\%$ \\
\hline Baik & 3 & 15 & 17 & 85 \\
Sedang & 6 & 30 & 3 & 15 \\
Buruk & 11 & 55 & 0 & 0 \\
\hline Jumlah & 20 & 100 & 20 & 100 \\
\hline
\end{tabular}

Tabel 4. Distribusi Frekuensi Persentase Kriteria Plak Indeks Sebelum dan Sesudah Menggunakan Sikat Gigi Pada Siswa-Siswi MTs Al-Wasliyah Pancur Batu Medan

\begin{tabular}{ccccc}
\hline $\begin{array}{c}\text { Kriteria } \\
\text { Plak }\end{array}$ & $\begin{array}{c}\text { Sebelum Menyikat } \\
\text { Gigi Dengan Sikat } \\
\text { Indeks }\end{array}$ & $\mathrm{N}$ & $\%$ & \multicolumn{2}{c}{$\begin{array}{c}\text { Sesudah Menyikat } \\
\text { Gigi Dengan Sikat } \\
\text { gigi }\end{array}$} \\
& 2 & 10 & 15 & $\%$ \\
\hline Baik & 7 & 35 & 5 & 25 \\
Sedang & 11 & 55 & 0 & 0 \\
Buruk & 20 & 100 & 20 & 100 \\
\hline Jumlah & & & & \\
\hline
\end{tabular}

Tabel 5. Distribusi Frekuensi Persentase Kriteria Plak Indeks Sebelum dan Sesudah menyikat Gigi Pada Siswa-Siswi MTs Al-Wasliyah Pancur Batu Medan

\begin{tabular}{ccccc}
\hline $\begin{array}{c}\text { Kriteria } \\
\text { Plak }\end{array}$ & \multicolumn{2}{c}{$\begin{array}{c}\text { Sebelum Menyikat } \\
\text { Gigi }\end{array}$} & \multicolumn{2}{c}{$\begin{array}{c}\text { Sesudah Menyikat } \\
\text { Gigi }\end{array}$} \\
Indeks & $\mathrm{N}$ & $\%$ & $\mathrm{~N}$ & $\%$ \\
\hline Baik & 5 & 12.5 & 32 & 80 \\
Sedang & 13 & 32.5 & 8 & 20 \\
Buruk & 22 & 55 & 0 & 0 \\
\hline Jumlah & 40 & 100 & 40 & 100 \\
\hline
\end{tabular}

Tabel 6. Distribusi Frekuensi Persentase Perbandingan Penurunan Rata-Rata Plak Indeks Pada Siswa-Siswi MTs Al-Wasliyah Pancur Batu Medan

\begin{tabular}{|c|c|c|c|c|}
\hline \multirow{2}{*}{$\begin{array}{c}\text { Jenis } \\
\text { Penggunaan }\end{array}$} & \multicolumn{2}{|c|}{$\begin{array}{c}\text { Rata-rata Plak } \\
\text { Indakes }\end{array}$} & \multirow{2}{*}{$\begin{array}{c}\text { Penurunan } \\
\text { Plak } \\
\text { indeks }\end{array}$} & \multirow{2}{*}{$\begin{array}{c}\text { Persentase } \\
\%\end{array}$} \\
\hline & Sebelum & Sesudah & & \\
\hline Siwak & 1.90 & 0.51 & 1.39 & 73 \\
\hline Sikat Gigi & 1.95 & 0.64 & 1.31 & 67 \\
\hline
\end{tabular}

Tabel 7. Uji Mann-Whitney

\begin{tabular}{lccccc}
\hline $\begin{array}{l}\text { INDEKS } \\
\text { PLAK }\end{array}$ & $\mathbf{N}$ & $\begin{array}{c}\text { MEAN } \\
\text { RANK }\end{array}$ & $\begin{array}{c}\text { Std. } \\
\text { deviasi }\end{array}$ & $\begin{array}{c}\text { MANN- } \\
\text { WHITE } \\
\text { Y }\end{array}$ & p \\
\hline $\begin{array}{l}\text { AWAL } \\
\text { SIWAK }\end{array}$ & 20 & 19.83 & .709 & 186.500 & 0.685 \\
$\begin{array}{l}\text { SIKAT } \\
\text { GIGI }\end{array}$ & 21.18 & & & \\
$\begin{array}{l}\text { AKHIR } \\
\text { SIWAK }\end{array}$ & 20 & 20.00 & .385 & 190.000 & 0.681 \\
$\begin{array}{l}\text { SIKAT } \\
\text { GIGI }\end{array}$ & 21.00 & & & \\
\hline
\end{tabular}

\section{PEMBAHASAN}

Penelitian ini mengambil sampel 40 siswa/i MTs Al-Wasliyah Pancur Batu Deli Serdang yang dipilih secara acak untuk seluruh kelas II yang dibagi menjadi 2 kelompok. Kelompok satu menyikat gigi dengan siwak dan kelompok dua menyikat gigi dengan sikat gigi. Dari hasil penelitian yang telah dilakukan maka diketahui bahwa banyak siswa/i yang memiliki angka indeks plak yang tinggi yang berarti rendahnya tingkat kebersihan gigi dan mulut siswa. Hal ini disebabkan karena kurangnya pengetahuan cara menjaga kebersihan gigi dan mulut.

Setelah dilakukan penelitian dapat dilihat bahwa rata-rata plak indeks pada sampel sebelum menggunakan siwak sebesar 1.90 dan menggunakan sikat gigi sebesar 1.95. pada sampel sesudah menggunakan siwak sebesar 0.51 dan menggunakan sikat gigi sebesar 0.64.

Dari hasil uji Mann-whitney tidak ada perbedaan pengaruh menyikat gigi dengan siwak dan sikat gigi dalam menurunkan indeks plak, jadi Hipotesis tidak ditolak, akan tetapi siwak lebih efektif dalam menghilangkan indeks plak melihat perhitungan yang didapat penurunan plak indeks pada siwak sebesar 1.39 sedangkan sikat gigi sebesar 1.31.

Sikat gigi lebih banyak dan mudah ditemukan di pasaran dibandingkan dengan siwak. Sikat gigi biasa bervariasi dan harganya relatif murah dan kebanyakan orang yang menggunakan sikat gigi biasa. Siwak biasanya digunakan oleh bangsa Arab dan orang-orang yang beragama Muslim, karena selain pembersih gigi siwak juga sebagai sunnah Rasulullah SAW yang diriwayatkan dari Bukhori dan Muslim. Menurut laporan Lewis (1982), siwak sangat efektif sebagai alat pembersih mulut, ditemukan sejumlah besar klorida, flour ,trimetilamin dan resin. Kemudian dari hasil penelitian Farooqi dan Srivastava (1990) ditemukan silika, sulfur dan vitamin c. Kandungan tersebut sangat bermanfaat bagi kesehatan gigi dan mulut dimana trimetilamin dan vitamin c membantu penyembuhan dan perbaikan jaringan gusi. Klorida bermanfaat menghilangkan noda pada gigi, sedangkan silika dapat bereaksi sebagai penggosok, kemudian keberadaan sulfur dikenal dengan rasa hangat dan bau yang khas. Penggunaan siwak dan sikat gigi bila digunakan dengan teknik yang benar, maka kedua-duanya dapat digunakan untuk membersihkan plak dengan efektif. Banyak orang tidak menggunakan siwak dikarenakan bau dan rasanya yang khas dan juga sebagian besar tidak mengerti dan tidak mengetahui manfaat siwak, oleh sebab 
itu banyak orang lebih memilih menggunakan sikat gigi biasa.

\section{SIMPULAN}

Dari hasil penelitian yang telah dilakukan oleh peneliti maka didapatkan kesimpulan bahwa :

1. Plak Indeks pada sampel sebelum menyikat gigi dengan menggunakan siwak sebesar 38.1 dengan rata-rata 1.90 dan sesudah menyikat gigi dengan menggunakan siwak sebesar 10.3 dengan rata-rata 0.51 .

2. Plak Indeks pada sampel sebelum menyikat gigi dengan menggunakan sikat gigi sebesar 37.1 dengan rata-rata 1.95 dan sesudah menyikat gigi dengan menggunakan sikat gigi sebesar 12.2 dengan rata-rata 0.54 .

3. Persentase kriteria plak indeks sebelum menyikat dengan kriteria baik didapat 5 orang siswa dengan persentase $12.5 \%, 13$ orang siswa dengan kriteria sedang 32.5\%, 22 orang siswa dengan kriteria buruk 55\%. Dan sesudah menyikat gigi dengan kriteria baik didapat 32 orang siswa dengan persentase $80 \%, 8$ orang siswa dengan kriteria sedang 20\%, tidak ada siswa dengan kriteria buruk $0 \%$.

4. Siwak lebih efektif dalam menghilangkan plak dibandingkan dengan sikat gigi biasa. Hal ini dapat dilihat dari perbedaan penurunan plak indeks setelah melakukan penggunaan siwak lebih besar penurunannya sebesar 1.39. sedangkan penurunan plak indeks sebesar 1.31 .

\section{SARAN}

Dengan selesainya penelitian ini, diharapkan :

1. Kepada siswa/i MTs Al-Wasliyah Pancur Batu Medan supaya menambah wawasan dan ilmu pengetahuan dalam menjaga kesehatan gigi dan mulut.

2. Kepada orang tua dan guru murid agar memberikan perhatian lebih dan mendidik anak dalam memelihara kesehatan gigi dan mulut serta meningkatkan penyuluhan tentang kesehatan gigi dan mulut melalui program UKGS.

3. Untuk tetap menjaga kebersihan gigi dan mulut dengan cara menyikat gigi minimal $2 \mathrm{x}$ sehari, pagi setelah makan dan malam sebelum tidur serta perhatikan juga teknik, frekuensi dan waktu menyikat gigi.
4. Penelitian ini dapat memotivasi kita semua dalam menggunakan siwak dan sikat gigi dalam menjaga kesehatan gigi dan mulut.

5. Kepada peneliti yang lain untuk lebih dalam mengkaji ilmu tentang siwak dan sikat gigi dalam penelitian selanjutnya

\section{DAFTAR PUSTAKA}

Admin,

2009.

Gusi merah. <http:/gusimerah.blogspot.com/2009/06/kenalimanfaat-sehat-siwak-atau-miswak.html].

Bastomi A., 2011. Selalu belajar untuk bersabar. $<$ http://abusalma.wordpress.com/2007/01/24/siwakkeajaiban-dalam-sunnah-nabi/

Depkes,. 1995. Pedoman Pelayanan Kesehatan Gigi dan Mulut Ibu Hamil, Ibu Menyusui, Balita dan Anak Prasekolah Secara Terpadu di RS dan Puskesmas. Jakarta.

Margareta., 2012. 101 Tips Dan terapi alami agar Gigi Putih dan Sehat. Yogyakarta: pustaka cerdas.

Notoatmodjo., 2010. Metodologi Penelitian Kesehatan. Rineka Cipta. Jakarta.

Pintauli., Hamada., 2008. Menuju Gigi dan Mulut Sehat Pencegahan dan Pemeliharaan. USU press Medan.

Panjaitan M,. 1996. Ilmu Pencegahan Karies Gigi. Sumatera Utara: IKJ press.

Prama PoolExpert,. 2009. 7 Khasiat Penting Menyikat Gigi dengan Siwak atau Miswak $<$ http://sunahsiwak.blogspot.com/2009/09/7khasiat-penting-menyikat-gigi-dengan.html].

Roeslan, B.O., 2002. Imunologi Oral Kelainan di dalam Rongga Mulut. FKUI. Jakarta.

Salma A,. 2005. Keajaiban Dalam Sunnah Nabi. <http://abusalma.wordpress.com/2007/01/24/siwakatau-miswak-merupakan.html].

Sofyan Ali,. 2010. Keutamaan Menggunakan Siwak Dibanding Sikat Gigi. <mujahiddin-

Salma A,. 2005. Keajaiban Dalam Sunnah Nabi. <http://abusalma.wordpress.com/2007/01/24/siwakatau-miswak-merupakan.html]

Wikipedia,. 2009.

Siwak. <http://id.wikipedia.org/wiki/Siwak].

Wikipedia,. $2007 . \quad$ Sikat $<$ http://id.wikipedia.org/wiki/Sikat_gigi

Gigi.

Wikipedia,. 2009

Siwak. <http://id.wikipedia.org/wiki/Siwak].

Wikipedia,. $2007 . \quad$ Sikat <http://id.wikipedia.org/wiki/Sikat_gigi
Gigi. 